\title{
Histocompatibility antigens in coal miners with pneumoconiosis
}

\author{
C A SOUTAR, ${ }^{1}$ I COUTTS,${ }^{2}$ W RAYMOND PARKES,${ }^{3}$ I A DODI,${ }^{4} \mathrm{~S}$ GAULD,${ }^{1} \mathrm{~J}$ E CASTRO,${ }^{5}$ \\ AND M TURNER-WARWICK ${ }^{6}$ \\ From the Institute of Occupational Medicine, ${ }^{1}$ Edinburgh EH8 9SU, Bristol and Weston Health District \\ (Teaching), ${ }^{2}$ Bristol Royal Infirmary, Bristol BS2 8HW, Pneumoconiosis Medical Panel, ${ }^{3}$ London NW1 2DG, \\ Royal Postgraduate Medical School, ${ }^{4}$ Hammersmith Hospital, London W12 0HS, 146 Harley St, London \\ W1, ${ }^{5}$ Cardiothoracic Institute, ${ }^{6}$ London SW3 6HP, UK
}

ABSTRACT Twenty-five histocompatibility antigens have been measured in 100 coal miners with pneumoconiosis attending a pneumoconiosis medical panel and the results compared with a panel of 200 normal volunteers not exposed to dust. Chest radiographs were read independently by three readers according to the ILO U/C classification. On a combined score, 40 men were thought to have simple pneumoconiosis and 60 men complicated pneumoconiosis. The number of antigens tested and associations between antigens caused difficulties in assessing the statistical significance of differences in prevalence of antigens between groups of men. Using stringent criteria for statistical significance, no significant differences were found in antigen prevalences between miners and controls, or miners with simple or complicated pneumoconiosis. When a less stringent statistical approach was applied, three antigens appeared to have abnormal prevalences in these 100 miners by comparison with the normal volunteers. More detailed examination of these antigen prevalences in relation to radiographic category of pneumoconiosis did not provide any supportive evidence that these slight associations were of statistical or clinical significance. Reports on histocompatibility antigens in miners with pneumoconiosis are reviewed briefly and the results compared. There is no good evidence that any of the histocompatibility antigens so far tested are associated with a clinically important altered risk of simple or complicated pneumoconiosis when dust is inhaled.

Coal pneumoconiosis is caused by respirable coalmine dust ${ }^{12}$ but there is unexplained variation in the attack rate of simple pneumoconiosis in relation to respirable dust exposure, and the reasons for the development of complicated pneumoconiosis (progressive massive fibrosis) in some individuals are poorly understood. ${ }^{3}$ Inherited constitutional differences in individual response to respirable dust inhalation may possibly contribute to this variation.

Reports ${ }^{4-6}$ have suggested that miners with certain types of pneumoconiosis may have abnormal prevalences of histocompatibility antigens, though agreement between studies has been poor.

In this study histocompatibility lymphocyte antigens have been measured in 100 coal miners with pneumoconiosis attending the London Pneumoconiosis Medical Panel, and the results compared with a panel of 200 normal volunteers. Internal com-

Received 6 October 1981 Accepted 6 May 1982 parisons have been possible between miners with simple pneumoconiosis (small rounded opacities) and those with complicated pneumoconiosis (large opacities, with or without small opacities).

\section{Methods}

Coal miners and ex-miners attending the pneumoconiosis medical panels in London and Canterbury for the purpose of claiming a pension on the grounds of disability from pneumoconiosis were asked to take part in the study if, in the opinion of one of us (WRP), the chest radiograph showed category 1 pneumoconiosis or greater. Enrolment was consecutive except for men unwilling to donate a blood sample. The men had worked predominantly in Welsh, Kentish, and Midland mines. The venous samples were added to tissue culture media at room temperature and transported by car to the laboratory. Intervals between venesection and cell separation and freezing ranged from seven to 17 hours. Clinical 
and occupational histories were recorded systematically.

Twenty-five HLA-A and B antigens were estimated by a standard method. ${ }^{7}$ Comparisons were made with a normal control group consisting of a panel of 200 healthy people of either sex recruited from hospital and laboratory staff and visitors. The similarities between prevalences in this control group and other published prevalences found in Britain have been described.

The chest radiographs were read independently by three readers (MTW, WRP, CAS) and results recorded according to the ILO U/C International Classification of Radiographs of the Pneumoconioses. ${ }^{8}$

In a preliminary analysis the overall distribution of differences in antigen prevalences between groups was examined. Subsequently prevalences of each tissue antigen were examined separately by two-bytwo contingency table. The p-value thus obtained may be multiplied by the number of antigens tested to obtain a more realistic estimate of probability." A continuity correction has not been used, ${ }^{10}$ and it has not been possible to take account of associations between antigens.

\section{Results}

\section{POPULATION}

Complete data were obtained from 100 men. Achievement of this exact figure after excluding men for reason of inadequate data was by chance.. The mean age of the men was $64 \cdot 9$ years, range $46-86$. The mean time spent working underground for those with simple pneumoconiosis was $38 \cdot 8$ years (range $10-53$ ) and for those with progressive massive fibrosis 31.0 years (range 6-53).
CHEST RADIOGRAPHS

Tables 1 and 2 show the prevalences of categories of small rounded opacities and large opacities recorded by each reader. There was good agreement between readers on the presence of large opacities: in 51 radiographs all three readers agreed that large opacities were present, in nine two readers agreed, and in six only one reader thought they were present. In view of this good agreement, the readings for the presence of large opacities were combined into a single score, based on majority verdict, for the purposes of comparison with antigen prevalences. By this means $\mathbf{4 0}$ men were deemed to have small rounded opacities without large opacities, and 60 men to have large opacities with or without small opacities.

Tables 3 and 4 show the agreement between readers on the categories of profusion and type of small opacities in individual radiographs in which no reader or only one reader recorded the presence of large opacities. There were systematic differences between readers in the categories recorded-for example, reader 1 recorded more radiographs in low categories of profusion than reader 2 , and reader 3 recorded more radiographs in high categories of profusion than reader 2 . Nevertheless, the agreement shown was greater than would be expected to occur by chance. In comparing these categories with HLA antigens each reader's results were considered separately, without using a combined score.

\section{TISSUE ANTIGENS}

Table 5 shows the prevalences of 25 HLA antigens in 100 coal miners and 200 non-coal-mining controls. Examination of the overall distribution of differences in antigen prevalences between clinical groups did not suggest any abnormal distribution. Examination of individual antigen prevalences did not indicate any

Table 1 Prevalences of categories of opacities in 100 chest radiographs recorded by three readers

\begin{tabular}{|c|c|c|c|c|c|}
\hline \multirow[t]{2}{*}{ Reader } & \multicolumn{4}{|c|}{ Category of small opacities (large opacities not present) } & \multirow[t]{2}{*}{ Large opacities present } \\
\hline & $0 / 00 / 1$ & $1 / 0 \quad 1 / 1 \quad 1 / 2$ & $2 / 12 / 2 \quad 2 / 3$ & $3 / 23 / 3$ & \\
\hline $\begin{array}{l}1 \\
2 \\
3\end{array}$ & $\begin{array}{l}2 \\
0 \\
0\end{array}$ & $\begin{array}{l}19 \\
12 \\
10\end{array}$ & $\begin{array}{l}19 \\
20 \\
19\end{array}$ & $\begin{array}{r}2 \\
8 \\
12\end{array}$ & $\begin{array}{l}58 \\
60 \\
59\end{array}$ \\
\hline
\end{tabular}

Table 2 Prevalences of types of opacities recorded by three readers in 100 chest radiographs

\begin{tabular}{|c|c|c|c|c|c|c|c|}
\hline \multirow[t]{2}{*}{ Reader } & \multicolumn{3}{|c|}{ Type of small rounded opacity } & \multicolumn{3}{|c|}{ Category of large opacity } & \multirow[t]{2}{*}{ Other } \\
\hline & $p$ & $q$ & $r$ & $\bar{A}$ & $B$ & $C$ & \\
\hline $\begin{array}{l}1 \\
2 \\
3\end{array}$ & $\begin{array}{l}0 \\
4 \\
5\end{array}$ & $\begin{array}{l}25 \\
26 \\
22\end{array}$ & $\begin{array}{l}10 \\
10 \\
12\end{array}$ & $\begin{array}{l}23 \\
27 \\
10\end{array}$ & $\begin{array}{l}31 \\
26 \\
43\end{array}$ & $\begin{array}{l}4 \\
7 \\
6\end{array}$ & $\begin{array}{l}7 \\
0 \\
2\end{array}$ \\
\hline
\end{tabular}


Table 3 Agreement between readers on categories of profusion of small opacities in 40 radiographs where no reader or only one reader recorded the presence of large opacities. Where both rounded and irregular opacities were recorded, the higher category of profusion was used

\begin{tabular}{|c|c|c|c|c|c|c|c|}
\hline \multirow{2}{*}{$\begin{array}{l}\text { Category of any } \\
\text { small opacities }\end{array}$} & \multicolumn{7}{|c|}{ Readers } \\
\hline & I only & 2 only & 3 only & $I$ and 2 only & $I$ and 3 only & 2 and 3 only & All agree \\
\hline $\begin{array}{l}1 / 2 \text { or less } \\
2 / 1 \text { or greater } \\
3 / 2 \text { or greater }\end{array}$ & $\begin{array}{l}8 \\
0 \\
0\end{array}$ & $\begin{array}{l}2 \\
2 \\
1\end{array}$ & $\begin{array}{l}0 \\
5 \\
8\end{array}$ & $\begin{array}{l}4 \\
0 \\
0\end{array}$ & $\begin{array}{l}2 \\
2 \\
1\end{array}$ & $\begin{array}{l}0 \\
8 \\
4\end{array}$ & $\begin{array}{r}7 \\
17 \\
1\end{array}$ \\
\hline
\end{tabular}

Table 4 Agreement between readers on presence of three types of small rounded opacities in 40 radiographs where no reader or only one reader recorded the presence of large opacities

\begin{tabular}{|c|c|c|c|c|c|c|c|}
\hline \multirow{2}{*}{$\begin{array}{l}\text { Type of small } \\
\text { rounded opacity }\end{array}$} & \multicolumn{7}{|c|}{ Readers } \\
\hline & I only & 2 only & 3 only & I and 2 only & 1 and 3 only & 2 and 3 only & All agree \\
\hline $\begin{array}{l}\mathbf{P} \\
\mathbf{Q} \\
\mathrm{R}\end{array}$ & $\begin{array}{l}0 \\
1 \\
1\end{array}$ & $\begin{array}{l}3 \\
4 \\
2\end{array}$ & $\begin{array}{l}4 \\
4 \\
5\end{array}$ & $\begin{array}{l}0 \\
7 \\
2\end{array}$ & $\begin{array}{l}0 \\
2 \\
1\end{array}$ & $\begin{array}{l}1 \\
1 \\
1\end{array}$ & $\begin{array}{r}0 \\
14 \\
5\end{array}$ \\
\hline
\end{tabular}

Table 5 Antigen prevalences (\%) in 100 miners with pneumoconiosis and 200 non-mining controls. For three antigens, prevalence appeared to be statistically significantly different between miners and our controls. When the number of contingencies examined is allowed for, none of these differences is significant at conventional levels. Average prevalences from pooled British studies are shown in parentheses $(n=1004)$

\begin{tabular}{|c|c|c|c|c|c|c|}
\hline Antigen & & $\begin{array}{l}\text { Controls } \\
(n=200)\end{array}$ & $p$ & $\begin{array}{l}\text { All miners } \\
(n=100)\end{array}$ & $\begin{array}{l}\text { Miners with } \\
\text { simple } \\
\text { pneumoconiosis } \\
(n=40)\end{array}$ & $\begin{array}{l}\text { Miners with } \\
\text { complicated } \\
\text { pneumoconiosis } \\
(n=60)\end{array}$ \\
\hline $\begin{array}{l}\text { A1 } \\
\text { A2 } \\
\text { A3 } \\
\text { A9 } \\
\text { A10 } \\
\text { A11 } \\
\text { AW 19t } \\
\text { A28 } \\
\text { A29 } \\
\text { B5 } \\
\text { B7 } \\
\text { B8 } \\
\text { B12 } \\
\text { B13 } \\
\text { B14 } \\
\text { B15 } \\
\text { B16 } \\
\text { B17 } \\
\text { B18 } \\
\text { B21 } \\
\text { B22 } \\
\text { B27 } \\
\text { B35 } \\
\text { B37 } \\
\text { B40 }\end{array}$ & n & $\begin{array}{r}36 \cdot 5(32) \\
44 \cdot 5(44) \\
26 \cdot 0(26) \\
19 \cdot 5(18) \\
14 \cdot 5(10) \\
19 \cdot 5(13) \\
19 \cdot 0(28) \\
7 \cdot 5(10) \\
8 \cdot 0(10) \\
9 \cdot 0(10) \\
23 \cdot 5(23) \\
28 \cdot 0(25) \\
36 \cdot 0(29) \\
4 \cdot 5(5) \\
4 \cdot 5(7) \\
12 \cdot 5(12) \\
4 \cdot 5(8) \\
10 \cdot 0(8) \\
8 \cdot 5(10) \\
4 \cdot 0(5) \\
5 \cdot 5(5) \\
7 \cdot(9(9) \\
15 \cdot(0(17) \\
1 \cdot 5(3) \\
7 \cdot 5(12)\end{array}$ & $\begin{array}{l}* * \\
*\end{array}$ & $\begin{array}{r}33 \cdot 0 \\
44 \cdot 0 \\
29 \cdot 0 \\
13 \cdot 0 \\
14 \cdot 0 \\
6 \cdot 0 \\
17 \cdot 0 \\
17 \cdot 0 \\
8 \cdot 0 \\
6 \cdot 0 \\
29 \cdot 0 \\
33 \cdot 0 \\
45 \cdot 0 \\
1 \cdot 0 \\
8 \cdot 0 \\
12 \cdot 0 \\
2 \cdot 0 \\
11 \cdot 0 \\
2 \cdot 0 \\
9 \cdot 0 \\
3 \cdot 0 \\
2 \cdot 0 \\
11 \cdot 0 \\
1 \cdot 0 \\
14 \cdot 0\end{array}$ & $\begin{array}{r}30 \cdot 0 \\
45 \cdot 0 \\
25 \cdot 0 \\
15 \cdot 0 \\
17 \cdot 5 \\
10 \cdot 0 \\
10 \cdot 0 \\
17 \cdot 5 \\
7 \cdot 5 \\
7 \cdot 5 \\
22 \cdot 5 \\
40.0 \\
45 \cdot 0 \\
2 \cdot 5 \\
5 \cdot 0 \\
12 \cdot 5 \\
2.5 \\
15 \cdot 0 \\
0.0 \\
7 \cdot 5 \\
2.5 \\
0.0 \\
15 \cdot 0 \\
0 \cdot 0 \\
7 \cdot 5\end{array}$ & $\begin{array}{c}35 \cdot 5 \\
43 \cdot 2 \\
31 \cdot 6 \\
11 \cdot 7 \\
11 \cdot 7 \\
3 \cdot 3 \\
21 \cdot 7 \\
16 \cdot 7 \\
8 \cdot 3 \\
5 \cdot 0 \\
33 \cdot 3 \\
28 \cdot 3 \\
45 \cdot 0 \\
0 \cdot 0 \\
10 \cdot 0 \\
11 \cdot 7 \\
1 \cdot 7 \\
8 \cdot 3 \\
3 \cdot 3 \\
10 \cdot 0 \\
3 \cdot 3 \\
3 \cdot 3 \\
8 \cdot 3 \\
1 \cdot 7 \\
18 \cdot 3 * \pm\end{array}$ \\
\hline
\end{tabular}

${ }^{* *} \mathrm{p}<0 \cdot() 1$ (not allowing for number of contingencies tested).

${ }^{*} p<0 \cdot(5)$ (not allowing for number of contingencies tested).

$\dagger$ Includes A30, 31, 32, 33.

$\mp$ Compared with controls only.

statistically significant differences between miners and controls when allowance was made for the number of contingencies tested. Comparisons of antigen prevalences between miners with small opacities only and miners with large opacities showed no statistically significant differences, whether or not the number of contingencies examined was allowed for (table 5). We chose to examine in more detail antigens A11, A28, and B18, since if the correction for number of contingencies had not been made, 
these antigens woud have appeared to be abnormally distributed between miners and controls. B40 was also examined in this way, for it appeared to be more common in men with complicated pneumoconiosis than in non-mining controls. Another three antigens, A1, B17, and B21 were examined similarly, since published reports by other workers have suggested that they may be more or less common in coal pneumoconiosis.

The distribution of these seven antigens was examined in relation to four categories $(0,1,2,3)$ of profusion of small opacities and presence of large opacities, and separately in relation to three categories $(\mathrm{p}, \mathrm{q}, \mathrm{r})$ of type of small opacity and three categories (A, B, C) of large opacity. Each reader's results were examined separately, and in no instance did the distribution of antigen prevalences show any suggestive pattern or trend between categories of profusion and type of small opacity or type of large opacity (though some of the subgroups were rather small). Thus no positive support was found for the existence of statistically or clinically significant relationships between these antigens and simple or complicated coal pneumoconiosis.

The prevalences of antigens found in the control group were in most instances similar to those in pooled results from British studies of the same

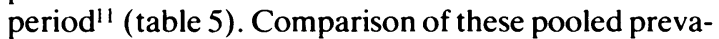
lences with those in the miners tended to confirm the differences in prevalences of A11, A28, and B18, though the difference for $A 11$ was less extreme. In addition, prevalences of AW19, B12, B16, and B27 appeared to be slightly different in the miners from these controls. Nevertheless, the distribution of these antigens in relation to profusion and type of opacities was examined as described above, and no convincing trends or patterns were identified.

\section{Discussion}

The histocompatibility phenotypes of 100 miners with pneumoconiosis have been examined and comparisons made with a laboratory-based panel of 200 healthy controls not exposed to dust. Comparisons were also made within the miners' group between those with simple and those with complicated pneumoconiosis.

The miners were selected consecutively over an 18-month period from those attending a pneumoconiosis medical panel, and these men were at least in part self-selected by their decision to apply for a disability pension. Once seen by the panel, men with abnormal radiographs are usually seen annually or biannually, and thereafter the reasons for a man's possible non-attendance and non-inclusion in this study would include illness and death. It is not known to what extent these factors have influenced the results, but it might be expected that if possession of one or more histocompatibility antigens influenced susceptibility to dust to an important practical degree, then an abnormal prevalence of these antigens would be found among these miners with pneumoconiosis.

In this study and in other published studies the number of antigens tested and associations between antigens have caused difficulty in assessing the statistical significance of apparent differences in prevalences of certain antigens. Multiplication of the pvalue for each antigen difference by the number of antigens tested has been recommended, ${ }^{9}$ and when this approach was used in the current work no statistically significant differences were found between miners and controls, nor between miners with simple or complicated pneumoconiosis.

In view of known associations between antigens. however, this statistical approach may have been too stringent to detect differences in prevalences of antigens between groups. When the results for each antigen were considered without correcting for the number tested, three antigens appeared to have statistically significantly different prevalences between miners and controls (there were no differences between simple and complicated pneumoconiosis even by this approach). Bearing in mind that this statistical treatment was probably not stringent enough, since apparently significant differences could have arisen by chance when dealing with this number of antigens, the prevalences of these antigens were examined in relation to the radiographic appearances studied in some detail. Thus subdividing the population according to several categories of profusion and type of opacity caused some of the groups to be rather small. Nevertheless, the distribution of these antigens between groups did not show any suggestive pattern or trend. While the small size of some of the groups could have obscured weak relationships between antigens and radiological appearance, the lack of any pronounced associations tends to suggest that the differences in prevalences between miners and controls were of little clinical significance as well as of uncertain statistical significance.

Comparisons of study subjects and controls measured in the same laboratory were clearly desirable. Nevertheless, regional or other differences between controls and the populations from which the miners were drawn might have caused inaccuracies. The antigen prevalences in our controls were in most cases similar to those found in (pooled) studies in Britain, and where differences in prevalences of antigens between miners and pooled controls appeared to be shown, these also were not supported by convincing trends or patterns in their distribution 
between radiographic categories. We conclude that clinically important associations between simple or complicated pneumoconiosis and certain histocompatibility antigens have not been shown in this study.

Other workers have reported apparent associations between types of coal pneumoconiosis and certain histocompatibility antigens, while often expressing reservations about the statistical significance of these results. One group reported a deficiency of antigen B18 in miners in Pennsylvania and West Virginia with simple pneumoconiosis compared with normal controls ${ }^{4}$ but could not confirm this negative association when the study was extended to a larger population. ${ }^{5} \mathrm{~A}$ study in South Wales ${ }^{6}$ did not confirm this association, and although our own study has shown a slightly lower prevalence of B18 in miners with pneumoconiosis than in control groups, the only two miners who had antigen B18 had complicated pneumoconiosis, and we regard this as tending to confirm that the B18 antigen does not provide important protection against coal pneumoconiosis when dust is inhaled.

The results of the completed study of miners in Pennsylvania and West Virginia $^{5}$ suggested that antigen Al was protective against coal pneumoconiosis in general, but neither the South Wales ${ }^{6}$ study nor our own have confirmed this. The South Wales ${ }^{6}$ study found a decreased prevalence of antigen B21 in miners with coal pneumoconiosis of all types, but this was not confirmed by our study (the American study did not include this antigen). These workers also found weaker associations of antigens B17 and B22 with certain categories of pneumoconiosis, which the American study did not confirm. Our study showed a random distribution of antigen B17, and only three miners had antigen B22; two of these had complicated pneumoconiosis, suggestive evidence against any protective associations of this antigen.

Thus three studies of different mining populations have failed to show reproducible associations between simple or complicated pneumoconiosis and histocompatibility antigen phenotypes. We conclude that there is no present evidence that any of the histocompatibility antigens so far examined are associated with a clinically important altered risk of simple or complicated pneumoconiosis.

We gratefully acknowledge financial support for this work from the Chest, Heart, and Stroke Association, and we also wish to thank Dr F J Darby, chief medical adviser (social security), Department of Health and Social Security, for permission to undertake this study.

\section{References}

I Jacobsen M, Rae S, Walton WH, Rogan JM. The relation between pneumoconiosis and dust exposure in British coal mines. In: Walton WH, ed. Inhaled particles III. Old Woking: Unwin Bros, 1971:903-19.

2 Reisner MTR. Results of epidemiological studies of pneumoconiosis in West German coalmines. In: Walton WH, ed. Inhaled particles III. Old Woking: Unwin Bros, 1971:921-31.

${ }^{3}$ McLintock JS, Rae S, Jacobsen M. The attack rate of progressive massive fibrosis in British coalminers. In: Walton WH, ed. Inhaled particles III. Old Woking: Unwin Bros, 1971:933-52.

${ }^{4}$ Heise ER. Major PC, Mentnech MS, Parrish EJ, Jordan AL. Morgan WKC. Predominance of histocompatibility antigens W18 and HLA-A1 in miners resistant to complicated coalworkers pneumoconiosis. In: Walton WH, ed. Inhaled particles IV. Oxford: Pergamon Press, 1977:495-507.

5 Heise ER, Mentnech MS, Olenchock SA, Kutz SA, Morgan WKC. Merchant JA, Major PC. HLA-Al and coalworkers pneumoconiosis. Am Rev Respir Dis 1979;119:903-8.

6 Wagner MMF, Darke C. HLA-A and B antigen frequencies in Welsh coalworkers with pneumoconiosis and Caplan's syndrome. Tissue Antigens 1979;14:165-8.

7 Terasaki PI. McCurdy B. McClelland J. Microdroplet lymphocyte cytotoxicity test. In: Ray JG, Scott RC, Hare DB, Harris CE, Kayhoe DE, eds. Manual of tissue typing techniques. Bethesda (MD): US Department of Health. Education and Welfare, Public Health Service, National Institutes of Health, 1972:50-5.

* International Labour Office. ILO U/C International classification of radiographs of the pneumoconioses, 1971. Geneva: ILO, 1972 (Occupational Safety and Health Series No 22.)

9 Grumet FC. HLA and disease associations. Transplant Proc IX 1977;9:1839-44.

${ }^{10}$ Feinberg SE. The analysis of cross-classified categorical data. Cambridge, Mass: MIT Press, 1977:21-2.

" Bodmer J, ed. The ABC of HLA (table S2). In: Kissmeyer-Nielsen F, ed. Histocompatibility testing. Report of the VI international histocompatibility workshop and conference, June/July 1975. Copenhagen: Munksgaard, 1975:31-2. 